\title{
Sappanone A Attenuates Allergic Airway Inflammation in Ovalbumin-Induced Asthma
}

\author{
Xueshibojie Liu ${ }^{a}$ Duo Yu ${ }^{b}$ Tiejun Wang ${ }^{b}$ \\ Departments of a Otolaryngology, Head and Neck Surgery and ${ }^{b}$ Radiotherapy, 2nd Hospital Affiliated to \\ Jilin University, Changchun, China
}

\section{Key Words}

Sappanone A · Asthma · Nrf2 signaling pathway ·

Th2 cytokines

\begin{abstract}
Background: Sappanone A (SA) is isolated from the heartwood of Caesalpinia sappan and exerts a wide range of pharmacological activities. In the present study, we investigated the protective effects of SA on allergic asthma in a murine model of ovalbumin (OVA)-induced asthma. Methods: $\mathrm{BALB} / \mathrm{c}$ mice were sensitized and challenged. Then, the mice were intraperitoneally injected with SA $(12.5,25$ and $50 \mathrm{mg} /$ kg) $1 \mathrm{~h}$ before OVA challenge; $24 \mathrm{~h}$ after the last challenge, the mice were sacrificed, and data were collected by different experimental methods. Results: The results showed that SA dose-dependently reduced inflammatory cell counts, levels of cytokines IL-4, IL-5 and IL-13, and OVA-specific IgE in bronchoalveolar lavage fluid. The level of IFN- $\gamma$ decreased by OVA was upregulated by the treatment with SA. Furthermore, SA was found to attenuate the airway inflammation and mucus hypersecretion induced by the OVA challenge. In addition, SA dose-dependently upregulated the expression of Nrf2 and HO-1. SA inhibited OVA-induced asthma by activating the Nrf2 signaling pathway. Conclusions: These data suggest that SA may have a potential use as a therapeutic agent for asthma.

๑) 2016 S. Karger AG, Basel
\end{abstract}

C 2016 S. Karger AG, Basel

$1018-2438 / 16 / 1703-0180 \$ 39.50 / 0$

\section{Introduction}

Asthma is a chronic inflammatory disease of the lung tissue that is characterized by the infiltration of inflammatory cells, airway inflammation, and airway hyperresponsiveness (AHR) [1,2]. In the last decades, asthma has been associated with significant morbidity and mortality worldwide [3,4]. Clinical and experimental investigations have demonstrated that Th2 type cytokines play a pivotal role in the pathophysiology of asthma. IL-4, IL-5, and IL-13 are important Th2 cytokines that have been reported to be involved in the development of asthma [5]. Recently, studies have shown that maintaining the Th1/ Th2 immune balance could protect against ovalbumin (OVA)-induced asthma [6, 7], and there have been several asthma treatment trials based on modulation of immune responses. Studies showed that many herbal medicines protected against OVA-induced asthma by regulating the Th1/Th2 balance $[8,9]$.

Sappanone A (SA), a homoisoflavanone that is isolated from the heartwood of Caesalpinia sappan, has been reported to have an anti-inflammatory effect. SA has been reported to inhibit IL-6 production in RAW264.7 cells [10]. Also, SA could inhibit LPS-induced iNOS expression

X.L. and D.Y. contributed equally to this article.

\section{KARGER}

E-Mail karger@karger.com

www.karger.com/iaa
Correspondence to: Dr. Tiejun Wang

Department of Radiotherapy

2nd Hospital Affiliated to Jilin University

Changchun, Jilin Province 130041 (China)

E-Mail wangtiejunlx@ sina.com 
and NO production. Furthermore, SA has been known to protect against LPS-induced mortality in mice [11]. The anti-inflammatory mechanism of SA was based on the inhibition of NF- $\kappa B$ activation. However, the protective effects of SA in a murine model of OVA-induced asthma have not been reported. Thus, in the present study, we investigated the protective effects and the potential mechanism of SA in a murine model of OVA-induced asthma.

\section{Materials and Methods}

\section{Chemicals and Reagents}

Dimethyl sulfoxide and OVA were purchased from Sigma (St. Louis, Mo., USA). Dexamethasone was obtained from Changle Pharmaceutical Co. (Xinxiang, Henan, China). Mouse IL-4, IL-5, and IL-13 ELISA kits were obtained from Biolegend (USA). Mouse IFN- $\gamma$ and IgE ELISA kits were obtained from eBioscience (USA). Nrf2 and HO-1 antibodies were purchased from Cell Signaling Technology Inc. (Beverly, Mass., USA). All other chemicals were of reagent grade.

\section{Animals}

Female BALB/c mice (6-8 weeks) were purchased from the Center of Experimental Animals of Jilin University (Jilin, China). Before the experiments, all the mice were fed under standard conditions to adopt the environment for 1 week. The mice were given distilled water and standard chow ad libitum. All animal experiments were performed in accordance with the Guide for the Care and Use of Laboratory Animals published by the US National Institutes of Health.

\section{Experimental Protocols}

Sixty mice were divided into six groups: the control group, OVA group, SA (50 mg/kg) group, and OVA + SA $(12.5,25$ and $50 \mathrm{mg} / \mathrm{kg}$ ) groups. On days 0 and 14 , the mice were sensitized via an intraperitoneal injection of $20 \mu \mathrm{g}$ of OVA emulsified with $2 \mathrm{mg}$ aluminum hydroxide in a total volume of $200 \mu \mathrm{PBS}$ ( $\mathrm{pH}$ 7.4) as an adjuvant. The mice were challenged by intranasal inhalations with $100 \mu \mathrm{g}$ OVA at days 21,22, and 23; $20 \mathrm{mg} \mathrm{SA}$ was dissolved in $0.2 \mathrm{ml}$ dimethyl sulfoxide and then dissolved in PBS to the concentrations of $12.5,25$ and $50 \mathrm{mg} / \mathrm{kg}$. The doses of SA used in this study were based on previous studies $[11,12]$. SA $(12.5,25$ and 50 $\mathrm{mg} / \mathrm{kg}$ ) was intraperitoneally given $1 \mathrm{~h}$ before the OVA challenge. The mice of the SA alone group received equal amounts of the vehicle for OVA. The mice of the control group received equal amounts of the vehicle for OVA and vehicle for SA.

\section{Collection of Blood and Bronchoalveolar Lavage Fluid}

Mice were anesthetized $24 \mathrm{~h}$ after the last challenge. Blood was collected by puncturing the vena cava and centrifuged at $4{ }^{\circ} \mathrm{C}$ $(3,000 \mathrm{rpm})$ for $10 \mathrm{~min}$, and the serum was stored at $-80^{\circ} \mathrm{C}$ for $\operatorname{IgE}$ assay. The lungs were washed twice by intratracheal instillation with cold PBS $(0.5 \mathrm{ml})$ to collect bronchoalveolar lavage fluid (BALF). The samples were collected and immediately centrifuged at $1,000 \mathrm{~g}$ at $4^{\circ} \mathrm{C}$ for $10 \mathrm{~min}$. The supernatants were stored at $-80^{\circ} \mathrm{C}$ for the determination of cytokines. The cell pellets were obtained and resuspended in PBS for total and differential cell counts.

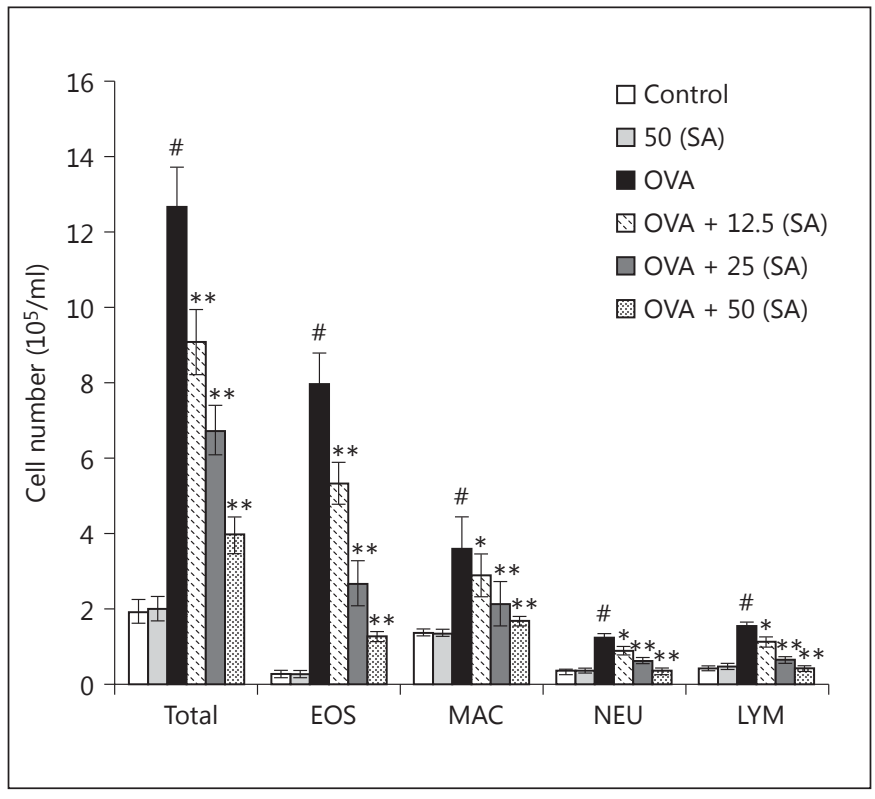

Fig. 1. Effects of SA on OVA-induced inflammatory cell count in the BALF. The values presented are the means \pm SEM of three independent experiments. $\mathrm{EOS}=$ Eosinophils; $\mathrm{MAC}=$ macrophages; $\mathrm{NEU}=$ neutrophils; LYM $=$ lymphocytes. ${ }^{*} \mathrm{p}<0.05$ versus control group; ${ }^{*} \mathrm{p}<0.05,{ }^{* *} \mathrm{p}<0.01$ versus OVA group.

\section{Enzyme-Linked Immunosorbent Assay}

The levels of IL-4, IL-5, and IL-13 in BALF were measured by using ELISA kits (Biolegend, USA) according to the manufacturer's instructions. The level of IFN- $\gamma$ in BALF and IgE in serum were quantified using ELISA kits (eBioscience, USA) according to the manufacturer's instructions.

\section{Histological Analysis}

Twenty-four hours after the last challenge, lung tissues were removed and fixed in 10\% neutral formalin. Then the tissues were sectioned, embedded in paraffin, and cut into 5 - $\mu \mathrm{m}$ sections. Lung sections were stained with hematoxylin and eosin (HE) to estimate lung histological changes. The histological changes in the lungs were scored as previously described [13]. Each histological characteristic was scored $0-5$.

\section{Western Blot Analysis}

Lung tissues were homogenized with a lysis buffer with protease and phosphatase inhibitors and then centrifuged at $3,000 \mathrm{~g}$ for $10 \mathrm{~min}$ at $4^{\circ} \mathrm{C}$. The supernatant was collected, and the total protein concentration was determined using the BCA protein assay kit. Twenty micrograms of proteins were separated by $10 \%$ SDSPAGE and electroblotted onto PVDF membranes. The membranes were blocked in 5\% nonfat milk for $2 \mathrm{~h}$ at room temperature. Then, the membranes were incubated overnight at $4^{\circ} \mathrm{C}$ with specific antibodies against Nrf2 and HO-1. After washing three times, the membranes were incubated with HRP-labeled secondary antibodies. Finally, blots were tested by ECL plus Western Blotting Detection System (Amersham Life Sciences, UK). 


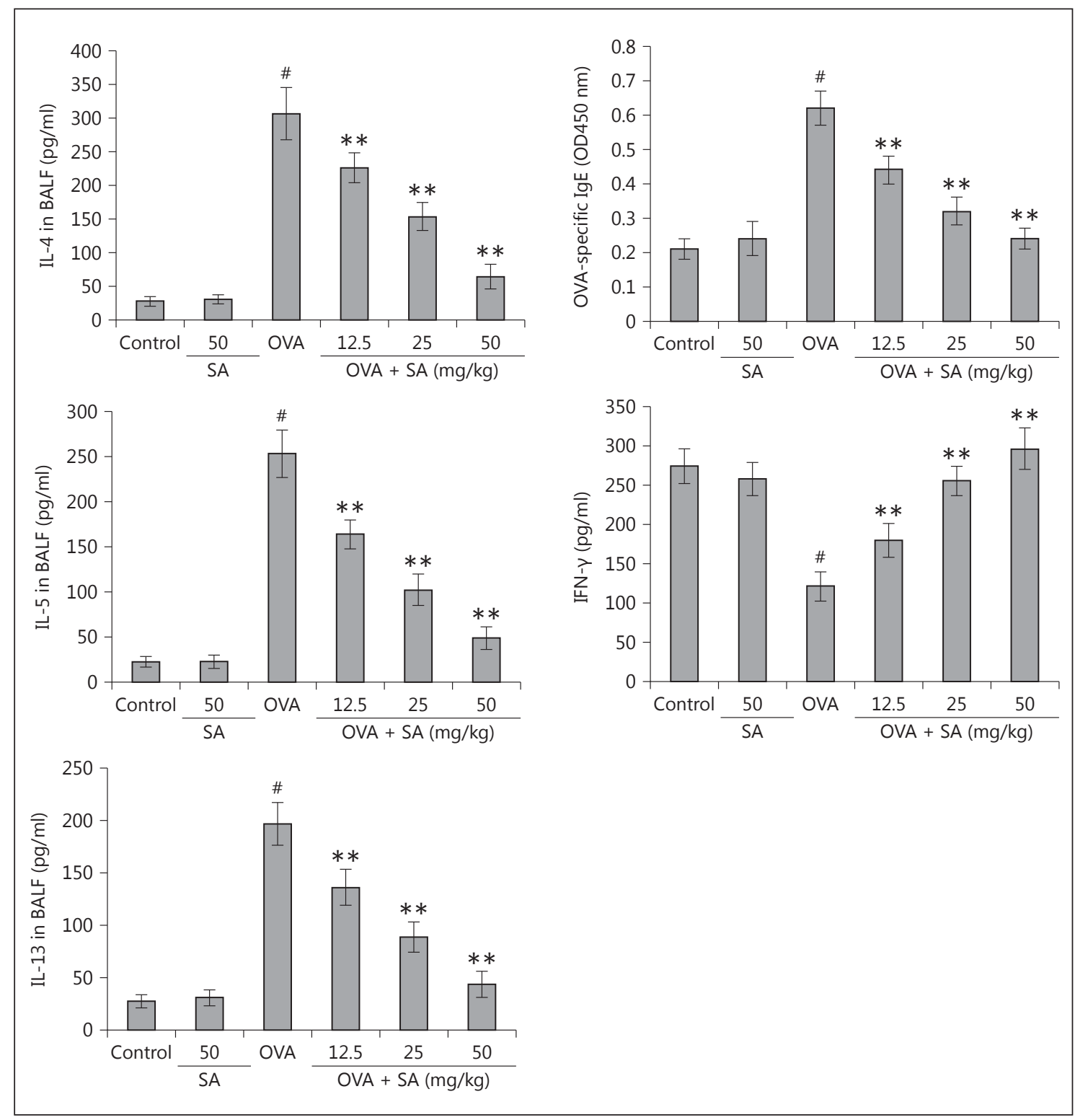

Fig. 2. Effects of SA on OVA-induced IgE in serum, IFN- $\gamma$, IL-4, IL-5, and IL-13 productions in BALF were detected by ELISA. The values presented are the means \pm SEM of three independent experiments. ${ }^{*} \mathrm{p}<0.05$ versus control group; ${ }^{* *} \mathrm{p}<0.01$ versus OVA group.

Evaluation of $A H R$

Twenty-four hours after the last challenge, mice were anesthetized using ketamine/xylazine. AHR was measured with a wholebody and invasive plethysmography (Buxco Electronics Inc., N.Y., USA) according to previous studies [14].

\section{Statistical Analysis}

Data were expressed as mean \pm SEM. The data were analyzed using one-way analysis of variance, followed by Tukey's post hoc test using the IBM SPSS Statistics (SPSS Inc., Chicago, Ill., USA). Statistical significance was set at $\mathrm{p}<0.05$ or $\mathrm{p}<0.01$.

\section{Results}

\section{SA Reduced Inflammatory Cells in BALF}

BALF was collected $24 \mathrm{~h}$ after the last OVA challenge; the effects of SA on the total cell and differential cell counts were evaluated in this study. As shown in figure 1, in comparison with the control group, the numbers of total cells, macrophages, neutrophils, eosinophils, and lymphocytes in BALF did not increase in the SA-treated 

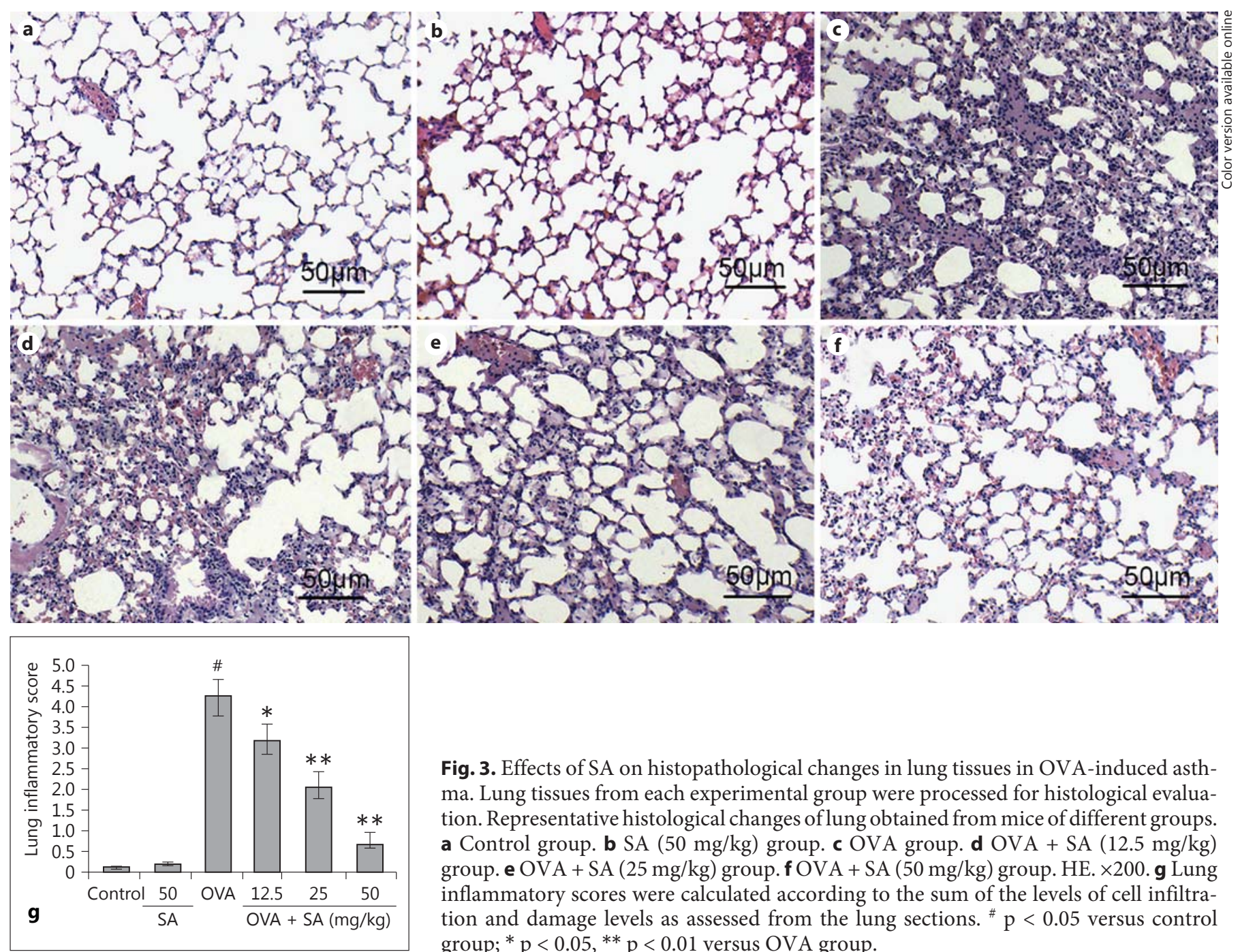

Fig. 3. Effects of SA on histopathological changes in lung tissues in OVA-induced asthma. Lung tissues from each experimental group were processed for histological evaluation. Representative histological changes of lung obtained from mice of different groups. a Control group. b SA $(50 \mathrm{mg} / \mathrm{kg})$ group. c OVA group. d OVA + SA $(12.5 \mathrm{mg} / \mathrm{kg})$ group. e OVA + SA $(25 \mathrm{mg} / \mathrm{kg})$ group. f OVA + SA $(50 \mathrm{mg} / \mathrm{kg})$ group. HE. $\times 200 . \mathbf{g}$ Lung inflammatory scores were calculated according to the sum of the levels of cell infiltration and damage levels as assessed from the lung sections. ${ }^{\#} \mathrm{p}<0.05$ versus control group; * $\mathrm{p}<0.05,{ }^{* *} \mathrm{p}<0.01$ versus OVA group.

group. In comparison with the control group, the numbers of total cells, macrophages, neutrophils, eosinophils, and lymphocytes in BALF were markedly increased in the OVA-treated group. Treatment with SA significantly inhibited the increases induced by OVA.

\section{Effects of SA on Th1/Th2 Cytokines in BALF and OVA-Specific IgE in Serum}

To detect the effects of SA on Th1/Th2 cytokine secretion, the levels of IL-4, IL-5, IL-13, and IFN- $\gamma$ were detected $24 \mathrm{~h}$ after the last challenge (fig. 2). The results showed that in comparison with the control group, the levels of IL-4, IL-5, IL-13 did not increase in the SA-treated group. The levels of IL-4, IL-5, IL-13 increased significantly in OVA-treated mice. However, the increases were inhibited by SA. The level of IFN- $\gamma$ was decreased by OVA and the decrease was upregulated by the treatment with SA. In addition, the level of IgE in serum was increased significantly in OVA-challenged mice. The treatment with SA dose-dependently inhibited OVAinduced IgE production.

\section{SA Ameliorated Pathological Changes of Lung Tissue}

In this study, HE staining was used to observe the histological features of lung tissue. As shown in figure 3, normal lung histology was observed in the control group and SA alone group. The lung tissues of OVA-treated mice showed significant pathological changes, such as inflammatory cell infiltration into the peribronchial areas, mucus overproduction and goblet cell hyperplasia. However, these pathological changes induced by OVA were significantly inhibited by SA. 


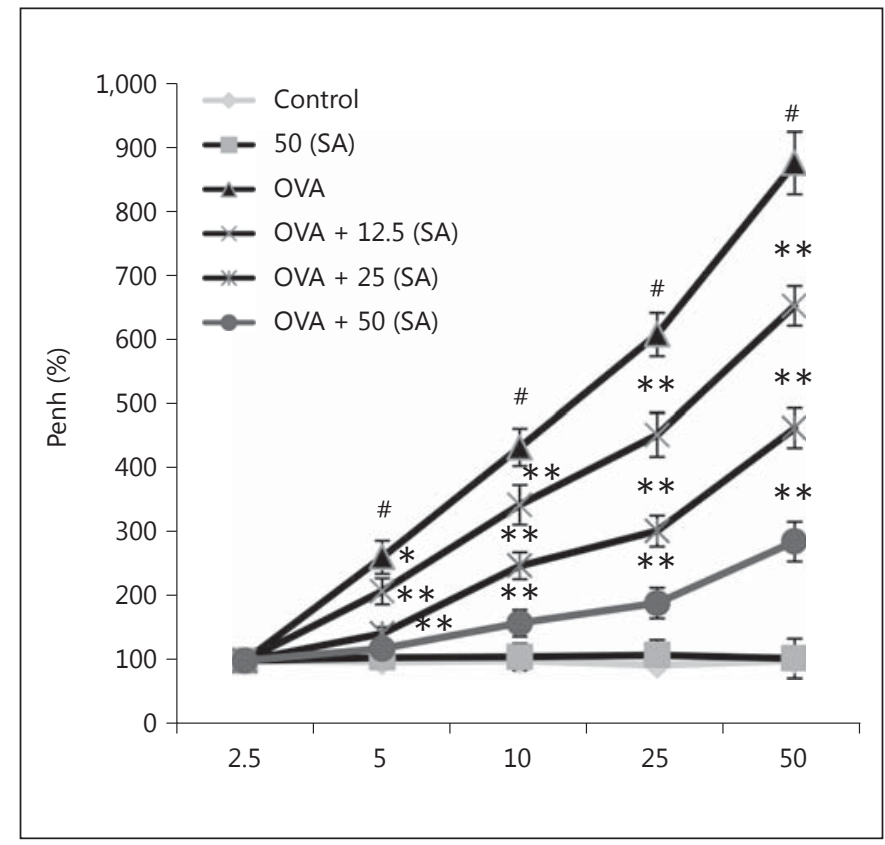

Fig. 4. SA alleviated OVA-induced AHR. The effects of SA on AHR were measured using noninvasive whole-body plethysmography (Buxco, Sharon, Conn., USA). The values presented are the means \pm SEM of three independent experiments. ${ }^{\#} \mathrm{p}<0.05$ versus control group; * $\mathrm{p}<0.05,{ }^{* *} \mathrm{p}<0.01$ versus OVA group.

\section{SA Inhibits AHR in OVA-Induced Mouse Asthma}

The effects of SA on AHR were detected by Penh in response to increased doses of methacholine. As shown in figure 4, in comparison with the control group, the Penh value did not increase in the SA-treated group. In comparison with the control group, the Penh value increased significantly in the OVA-treated group. However, the increase was dose-dependently inhibited by the treatment with SA.

\section{Effects of SA on the Nrf2 Signaling Pathway}

We assessed the effects of SA on the Nrf2 signaling pathway by Western blot analysis. As shown in figure 5, the levels of Nrf2 and HO-1 were decreased by OVA challenge when compared to the control group. However, the expression of Nrf2 and HO-1 were upregulated by the treatment with SA.

\section{Discussion}

In this study, using a mouse model of OVA-induced asthma, we investigated the protective effects of SA on allergic airway inflammation. We showed that the treatment with SA protected against OVA-induced asthma by regulating the Th1/Th2 balance.

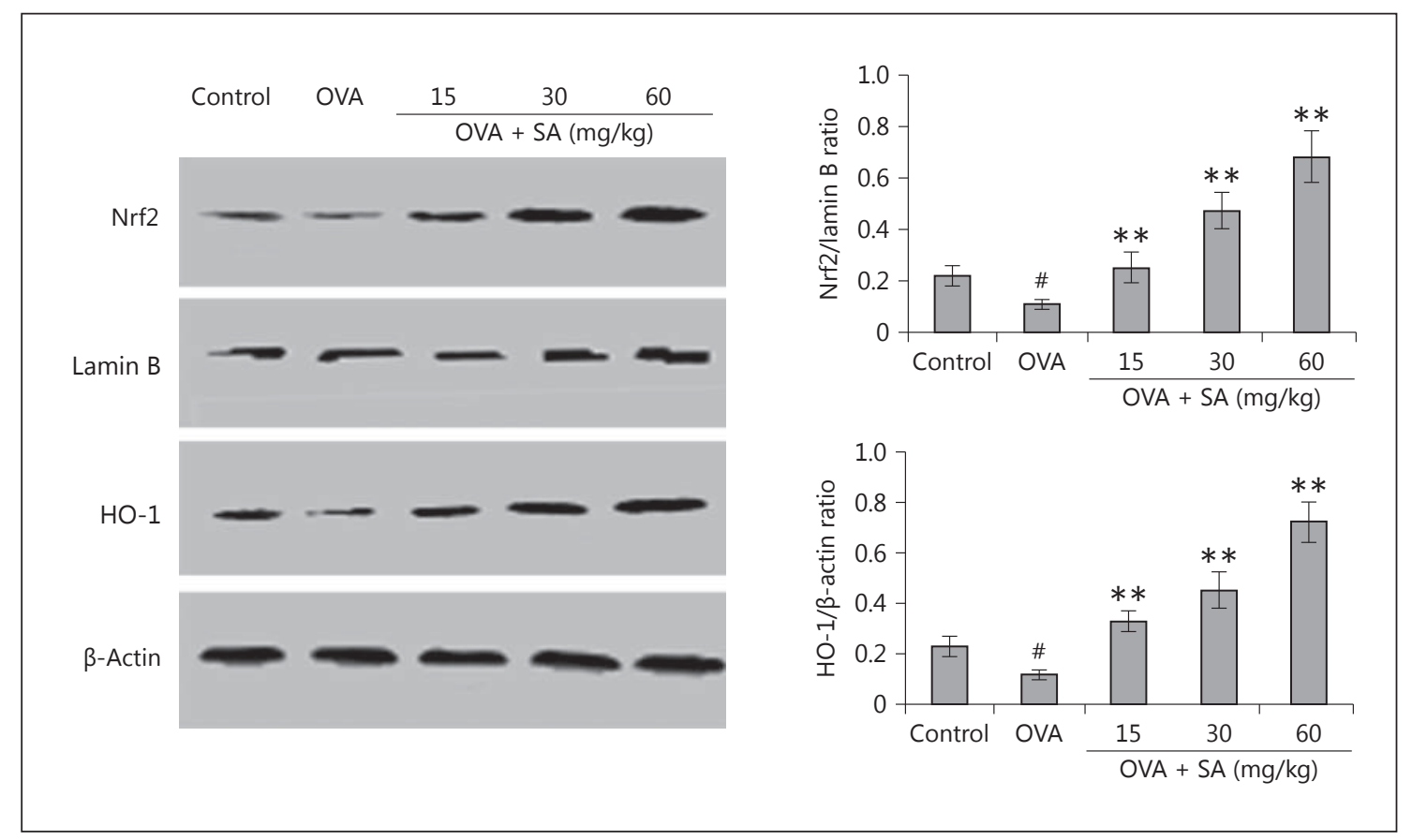

Fig. 5. Effects of SA on Nrf2 signaling pathway. The expression of Nrf2 and HO-1 was detected by Western blotting. The values presented are the means \pm SEM of three independent experiments. ${ }^{*} \mathrm{p}<0.05$ versus control group; ${ }^{* *} \mathrm{p}<0.01$ versus OVA group. 
Inflammation has been reported to play a critical role in the development of asthma $[15,16]$. Studies showed that an inflammatory phenotype (Th1 or Th2) is thought to be important as a host factor to modulate tissue injury [17]. Asthma is characterized by a Th2 type immune response, with increases in the number of eosinophils and other inflammatory cells, and increased amounts of Th2 cytokines such as IL-4, IL-5, and IL-13 [18, 19]. In this study, our results showed that SA significantly attenuated the infiltration of eosinophils and other inflammatory cells. Studies showed that many compounds protect against asthma by regulating the Th1/Th2 balance $[7,20]$. In this study, our results showed that SA regulated the Th1/Th2 balance, inhibition of IL-4, IL-5, and IL-13 production and upregulation of IFN- $\gamma$ production. Taken together, these results indicate that SA exerts its anti-asthmatic effect via regulation of the Th1/Th2 balance.

$\mathrm{Nrf2}$, a critical regulator, has been reported to play an important role in oxidative stress [21,22]. Nrf2 exhibited antioxidant effects by inducing phase II detoxifying enzymes, particularly the HO-1 $[21,23]$. Recently, Nrf2 has been reported to be a potential target for asthma [24]. Previous studies showed that many compounds exhib- ited their anti-asthma effects by activating the Nrf2 signaling pathway. Furthermore, studies showed that Nrf2 was involved in the regulation of the Th2/Th2 balance [25]. Nrf2-deficient mice showed an increase in the number of Th2 cells and Th2 cytokines in the lungs [26]. To investigate the anti-inflammatory mechanism of SA, the effects of SA on the Nrf2 signaling pathway were detected in this study. The results showed that the expression of Nrf2 and HO-1 was upregulated by the treatment with SA. The results indicated that SA protects against OVAinduced asthma by activating the Nrf2 signaling pathway.

In conclusion, the results of this study indicated that administration of SA effectively attenuates OVA-induced allergic airway inflammation. The mechanism of SA is associated with regulating the Th1/Th2 balance through activation of the Nrf2 signaling pathway. SA has a therapeutic potential for treating asthma.

\section{Disclosure Statement}

The authors have no conflict of interest to declare.

\section{References}

1 Wills-Karp M: Immunologic basis of antigeninduced airway hyperresponsiveness. Annu Rev Immunol 1999;17:255-281.

2 Cohn L, Elias JA, Chupp GL: Asthma: mechanisms of disease persistence and progression. Annu Rev Immunol 2004;22:789-815.

3 Suissa S, Ernst P: Inhaled corticosteroids: impact on asthma morbidity and mortality. J Allergy Clin Immunol 2001;107:937-944.

4 Williams TJ, Tuxen DV, Scheinkestel CD, Czarny D, Bowes G: Risk factors for morbidity in mechanically ventilated patients with acute severe asthma. Am Rev Respir Dis 1992; 146:607-615.

5 Kay A: Th2-type cytokines in asthma. Ann NY Acad Sci 1996;796:1-8.

6 Mazzarella G, Bianco A, Catena E, De Palma R, Abbate G: Th1/Th2 lymphocyte polarization in asthma. Allergy 2000;55:6-9.

7 Park H-J, Lee C-M, Jung ID, Lee JS, Jeong Y-I, Chang JH, Chun S-H, Kim M-J, Choi I-W, Ahn S-C: Quercetin regulates Th1/Th2 balance in a murine model of asthma. Int Immunopharmacol 2009;9:261-267.

8 Lee JS, Lee C-M, Jeong Y-I, Jung ID, Kim B-H, Seong E-Y, Kim J-I, Choi I-W, Chung HY, Park Y-M: D-Pinitol regulates Th1/Th2 balance via suppressing Th2 immune response in ovalbumin-induced asthma. FEBS Lett 2007;581:57-64.
9 Ma C, Ma Z, Liao X-L, Liu J, Fu Q, Ma S: Immunoregulatory effects of glycyrrhizic acid exerts anti-asthmatic effects via modulation of Th1/Th2 cytokines and enhancement of CD4+ CD25+ Foxp3+ regulatory $\mathrm{T}$ cells in ovalbumin-sensitized mice. J Ethnopharmacol 2013;148:755-762.

10 Chu M-J, Wang Y-Z, Itagaki K, Ma H-X, Xin P, Zhou X-G, Chen G-Y, Li S, Sun S-Q: Identification of active compounds from Caesalpinia sappan L. extracts suppressing IL-6 production in RAW 264.7 cells by PLS. J Ethnopharmacol 2013;148:37-44.

11 Lee S, Choi S-Y, Choo Y-Y, Kim O, Tran PT, Dao CT, Min B-S, Lee J-H: Sappanone A exhibits anti-inflammatory effects via modulation of Nrf2 and NF- $\kappa$ B. Int Immunopharmacol 2015;28:328-336.

12 Kang L, Zhao H, Chen C, Zhang X, Xu M, Duan H: Sappanone A protects mice against cisplatin-induced kidney injury. Int Immunopharmacol 2016;38:246-251.

13 Liu M-H, Lin A-H, Lee H-F, Ko H-K, Lee T-S, Kou YR: Paeonol attenuates cigarette smokeinduced lung inflammation by inhibiting ROS-sensitive inflammatory signaling. $\mathrm{Me}$ diators Inflamm 2014;2014:651890.
14 HuangFu T, Lim LH, Chua KY: Efficacy evaluation of Der $\mathrm{p} 1 \mathrm{DNA}$ vaccine for allergic asthma in an experimental mouse model. Vaccine 2006;24:4576-4581.

15 Lee KS, Lee HK, Hayflick JS, Lee YC, Puri KD Inhibition of phosphoinositide 3-kinase $\delta$ attenuates allergic airway inflammation and hyperresponsiveness in murine asthma model. FASEB J 2006;20:455-465.

16 Zuberi RI, Hsu DK, Kalayci O, Chen H-Y, Sheldon HK, Yu L, Apgar JR, Kawakami T, Lilly CM, Liu F-T: Critical role for galectin-3 in airway inflammation and bronchial hyperresponsiveness in a murine model of asthma. Am J Pathol 2004;165:2045-2053.

17 Steinman L: A brief history of Th17, the first major revision in the Th1/Th2 hypothesis of T cell-mediated tissue damage. Nat Med 2007; 13:139-145.

18 Hakonarson $\mathrm{H}$, Maskeri N, Carter C, Grunstein MM: Regulation of Th1- and Th2type cytokine expression and action in atopic asthmatic sensitized airway smooth muscle. J Clin Invest 1999;103:1077-1087.

19 Schmitz N, Kurrer M, Kopf M: The IL-1 receptor 1 is critical for Th2 cell type airway immune responses in a mild but not in a more severe asthma model. Eur J Immunol 2003;33 991-1000. 
20 Yuan Y, Yang B, Ye Z, Zhang M, Yang X, Xin C, Lin M, Huang P: Sceptridium ternatum extract exerts antiasthmatic effects by regulating Th1/Th2 balance and the expression levels of leukotriene receptors in a mouse asthma model. J Ethnopharmacol 2013;149:701-706.

21 Lee JM, Johnson JA: An important role of Nrf2ARE pathway in the cellular defense mechanism. J Biochem Mol Biol 2004;37:139-143.

22 Shih P-H, Yeh C-T, Yen G-C: Anthocyanins induce the activation of phase II enzymes through the antioxidant response element pathway against oxidative stress-induced apoptosis. J Agric Food Chem 2007;55:94279435.
23 Li N, Alam J, Venkatesan MI, Eiguren-Fernandez A, Schmitz D, Di Stefano E, Slaughter $\mathrm{N}$, Killeen E, Wang X, Huang A: Nrf2 is a key transcription factor that regulates antioxidant defense in macrophages and epithelial cells: protecting against the proinflammatory and oxidizing effects of diesel exhaust chemicals. J Immunol 2004;173:3467-3481.

24 Sussan TE, Gajghate S, Chatterjee S, Mandke P, McCormick S, Sudini K, Kumar S, Breysse PN, Diette GB, Sidhaye VK: Nrf2 reduces allergic asthma in mice through enhanced airway epithelial cytoprotective function. Am J Physiol Lung Cell Mol Physiol 2015;309:L27L36.
25 Kikuchi N, Ishii Y, Morishima Y, Yageta Y, Haraguchi N, Itoh K, Yamamoto M, Hizawa $\mathrm{N}$ : Nrf2 protects against pulmonary fibrosis by regulating the lung oxidant level and Th1/ Th2 balance. Respir Res 2010;11:31.

26 Rangasamy T, Guo J, Mitzner WA, Roman J, Singh A, Fryer AD, Yamamoto M, Kensler TW, Tuder RM, Georas SN: Disruption of Nrf2 enhances susceptibility to severe airway inflammation and asthma in mice. J Exp Med 2005;202:47-59. 